\title{
Relações subjetivas mediando o processo de constituição docente no espaço não escolar
}

\author{
Subjective relationships mediating the teaching constitution process in non school environment \\ Relaciones subjetivas mediante el proceso de constitución docente en espacio no escolar
}

Recebido: 14/03/2021 | Revisado: 20/03/2021 | Aceito: 09/04/2021 | Publicado: 18/04/2021

\author{
Sílvia Maria Costa Barbosa \\ ORCID: https://orcid.org/0000-0002-9197-1472 \\ Universidade do Estado do Rio Grande do Norte, Brasil \\ E-mail: silviacostab@yahoo.com.br \\ Hemaúse Emanuele da Silva \\ ORCID: https://orcid.org/0000-0001-7284-7305 \\ Universidade do Estado do Rio Grande do Norte, Brasil \\ E-mail: hemause@hotmail.com \\ Elisiana Nadia da Silva \\ ORCID: https://orcid.org/0000-0001-9392-6440 \\ Universidade do Estado do Rio Grande do Norte, Brasil \\ Email: elisiananadia@yahoo.com.br \\ Luana Oliveira Ferreira lima \\ ORCID: https://orcid.org/0000-0003-1237-9102 \\ Universidade do Estado do Rio Grande do Norte, Brasil \\ E-mail: luanna.lu.oliveira@gmail.com
}

\begin{abstract}
Resumo
O presente artigo tem como objetivo compreender as relações subjetivas constituídas por uma egressa do Curso de Pedagogia no espaço não-escolar. Para tanto, elegemos a seguinte problemática: como são constituídas as relações subjetivas por uma egressa do curso de Pedagogia no espaço não escolar? A colaboradora da nossa pesquisa é uma egressa do curso de Pedagogia da Universidade do Estado do Rio Grande do Norte - UERN, formada no contexto da nova matriz curricular, reformulada e implantada com base nas novas políticas públicas para o curso de Pedagogia e que trabalha no ambiente hospitalar. $\mathrm{O}$ arcabouço teórico-metodológico da pesquisa estão ancorados na Psicologia Sócio-Histórica à luz do Materialismo Histórico-Dialético de Marx e nos estudos de Vigotski e seus colaboradores, Leontiev e Luria. Trata-se de uma investigação de abordagem qualitativa, que adotou como procedimento de pesquisa a entrevista reflexiva e para análise das informações, os núcleos de significações elaborados por Aguiar e Ozella e reelaborada por Aguiar, Soares e Machado. A postura da pedagoga que atua na classe hospitalar colaboradora da nossa pesquisa se transforma conforme a dificuldade que enfrenta no espaço em que se encontra inserida para atender as diversas necessidades do seu dia-a-dia. Essa modificação acontece por meio das vivências subjetivas no espaço educativo que essa educadora se encontra inserida.
\end{abstract}

Palavras-chave: Ensino; Egressos; Pedagogia hospitalar; Subjetividade.

\begin{abstract}
This article aims to reveal understand the subjective relationships formed by a graduate of the Pedagogy Course in the non-school space. Therefore, we chose the following problem: how are subjective relations formed by a graduate of the Pedagogy course in the non-school space?The collaborator in our research is an alumnus of the Pedagogy course at the State University of Rio Grande do Norte - UERN, graduated in the context of the new curricular matrix, reformulated and implemented based on the new public policies for the Pedagogy course and who specializes in the hospital environment. The framework the oretical-methodological assumptions of the research are anchored in SocioHistorical Psychology in the light of Marx's Historical-Dialectic materialism and in the studies of Vygotsky and his collaborators, Leontiev and Luria. This is a qualitative approach investigation, which adopted as a research procedure the reflective interview and for information analysis, the nuclei of meanings elaborated by Aguiar and Ozella. The condition posture of conditionof the pedagogue engaged in the collaborative hospital context with the research is modified according to the need she faces in the environment in which she is inserted to meet her various day-to-day needs. This change happens through the subjective experiences in the educational space in which this educator is inserted.
\end{abstract}

Keywords: Teaching; Graduates; Hospital pedagogy; Subjectivity.

\section{Resumen}

Este artículo tiene como objetivo comprender las relaciones subjetivas que forma un egresado del Curso de Pedagogía en el espacio no escolar. Por tanto, elegimos el siguiente problema: ¿cómo se forman las relaciones subjetivas de un egresado de la carrera de pedagogía en el espacio no escolar? El colaborador en nuestra investigación es una graduada 
del curso de pedagogía en la Universidad Estatal de Río Grande del Norte - UERN, formada en el contexto de la nueva matriz curricular, reformulada e implementada en base a las nuevas políticas públicas para el curso de Pedagogía y que trabaja en el ambiente hospitalario. Los marco de referencia teórico-metodológicos de la investigación están anclados en la psicología sociohistórica a la luz del materialismo Histórico-Dialéctico de Marx y en los estudios de Vigotski y sus colaboradores, Leontiev y Luria. Esta es una investigación de enfoque cualitativo, que adoptó como procedimiento de investigación la entrevista reflexiva y para el análisis de la información, los núcleos de significados elaborados por Aguiar y Ozella. La postura de condición de la pedagoga que trabaja en la clase hospitalaria que colabora con la investigación se modifica de acuerdo con la necesidad que enfrenta en el espacio en el que se inserta para satisfacer a las diversas necesidades de su vida diaria. Esta modificación ocurre a través de las vivencias subjetivas en el espacio educativo en el que se inserta este educador.

Palabras clave: Ensenãnza; Graduados; Pedagogía hospitalaria; Subjetividad.

\section{Introdução}

Durante décadas da história da educação o pedagogo foi considerado um profissional de atuação exclusiva para o exercício da carreira docente, mas com o passar dos anos e o surgimento de necessidades, tendo em vista a sociedade contemporânea, o licenciado em Pedagogia amplia as possibilidades para atuar em espaços não escolares, haja vista, as novas Diretrizes Curriculares Nacionais para o curso de Pedagogia -DCNCP - Resolução CNE/CP nº 1, de 15 de maio de 2006 - que ressalva as mudanças na formação docente incipiente de egressos desde a sua formação inicial, principalmente no sentido de superar o modelo da racionalidade técnica.

Nesta perspectiva, a Universidade do Estado do Rio Grande do Norte - UERN atende as DCNCP e implanta no curso de Pedagogia um currículo que intenta formar um profissional habilitado para atuar em diferentes contextos, escolar e nãoescolar, uma vez que este passou a contemplar com maior intensidade as disciplinas pedagógicas e, consequentemente, gerar uma maior integração dessas com a realidade subjetiva do mercado de trabalho e com a demanda da sociedade atual.

Entre as mudanças, a formação para a prática profissional deve estar presente desde o início do curso não somente nas disciplinas pedagógicas, mas nos componentes curriculares, como por exemplo, os estudos introdutórios, os seminários temáticos e os estágios supervisionados I e II, nos quais o estudante conhece o futuro campo de trabalho, seja na Educação Infantil ou no Ensino Fundamental. No Estágio Supervisionado III, o graduando é designado a espaços não escolares em empresas, hospitais, ONGs e outros, como um novo campo de atuação do pedagogo. Com isso, percebemos o avanço significativo no que tange às possibilidades de novas práticas que atendam as diversidades dos espaços de trabalho não escolares que a licenciatura em Pedagogia oportuniza ao seu egresso.

Segundo a Resolução CNE/CP nº 1, de 15 de maio de 2006, em seu artigo 2,

As Diretrizes Curriculares para o curso de Pedagogia aplicam-se à formação inicial para o exercício da docência na Educação Infantil e nos anos iniciais do Ensino Fundamental, nos cursos de Ensino Médio, na modalidade Normal, e em cursos de Educação Profissional na área de serviços e apoio escolar, bem como em outras áreas nas quais sejam previstos conhecimentos pedagógicos (Brasil, 2006).

Diante disso, as Diretrizes Curriculares Nacionais- DCNs em seu artigo $5^{\circ}$, parágrafo IV entoam que o egresso do curso de Pedagogia deverá estar apto a "trabalhar, em espaços escolares e não-escolares, na promoção da aprendizagem de sujeitos em diferentes fases do desenvolvimento humano, em diversos níveis e modalidades do processo educativo".

Podemos compreender que o curso de Pedagogia pretende formar um profissional com habilitação para além dos muros da escola, isso porque o novo perfil conferido aos egressos da supracitada formação não se limita apenas ao espaço escolar, este agora é habilitado para atuar em espaços não escolares. E partindo desse conceito, o presente artigo tem como objetivo compreender as relações subjetivas constituídas por uma egressa do Curso de Pedagogia no espaço não escolar. A colaboradora da nossa pesquisa é uma egressa do curso de Pedagogia da Universidade do Estado do Rio Grande do Norte - 
UERN, formada no contexto da nova matriz curricular, reformulada e implantada com base nas novas políticas pública para o referido curso em discussão.

O presente trabalho está divido em quatro pontos distintos, mas interligados, para que o leitor venha compreender os processos que nos levaram e nos conduziram em todo trabalho aqui apresentado. No primeiro ponto, trazemos uma breve alusão sobre as competências pretendidas pelo curso de Pedagogia - UERN para com seu egresso, com ênfase no campo não escolar, por ser o campo de atuação do nosso sujeito de pesquisa.

Em seguida, na metodologia, apresentamos os pressupostos teórico-metodológicos da Psicologia Sócio-Histórica, com base em Vigotski (2007; 2009), Luria (2001) e estudiosos como Soares (2006), Bock e Aguiar (2016), entre outros. Vale destacar que esta Psicologia não estuda o sujeito como objeto, mas sim o processo histórico-cultural que o constitui e o envolve, buscando na sua subjetividade a resposta para a(s) indagação(ões) que surgem.

Para o processo de análise elegemos algumas categorias teóricas da Psicologia Sócio-Histórica, tais como: sentido e significado, atividade, subjetividade e afetividade, que tem base no materialismo histórico-dialético que são condicionados ao estudo da vida social, aos fenômenos da vida na sociedade, ao estudo desta e de sua história, ou seja, esta considera o meio e o todo, no processo totalitário e marxista. E conseguinte, será apresentado para uma melhor compreensão do leitor sobre o que é e como utilizamos a entrevista reflexiva como instrumento de produção das informações.

Nos resultados e discussão, para análise das informações utilizamos a sistematização e nomeação do núcleo de significação, teoria elaborada inicialmente por Aguiar e Ozella (2006) e reelaborado por Aguiar, Soares e Machado (2015). E por fim, apresentamos algumas considerações finais acerca das informações obtidas e do trabalho desenvolvido.

\section{O Pedagogo em Espaços não Escolares: Pedagogia Hospitalar}

Ao egresso de Pedagogia lhe foi conferido a missão de trabalhar com a formação de sujeitos de maneira integral, enfocando sua aprendizagem. Desta maneira, quando falamos no curso supracitado, nosso pensamento é direcionado imediatamente ao ensino escolarizado desenvolvido em espaços escolares; isso acontece porque seu significado é enraizado e construído socialmente e culturalmente no decurso de sua história, ou seja, esse pensamento é algo que se enraizou na cultura.

Vale ressaltar que esse significado é algo que vem mudando assim como a sociedade que vivemos e passa por constantes mudanças advindas dos avanços tecnológicos, científicos, mercado de trabalho. Para atender essas transformações tanto a sociedade quanto as políticas públicas para a formação inicial de professores, em especial o curso de Pedagogia, redirecionou as DCNCP para atender as novas demandas do mercado de trabalho vigente. Isso se evidencia com as novas Diretrizes Curriculares Nacionais para o curso de Pedagogia que foram aprovadas pelo Conselho Nacional de Educação em 2006, cuja expectativa de docência apresentada nas diretrizes transcende o ato de ensinar e transcende os limites da sala de aula e a atuação do pedagogo em espaços diversos é assegurada por lei, mais especificamente por meio do artigo $5^{\circ}$, inciso IV da Resolução CNE/CP n ${ }^{\circ}$ 1, 15 de maio de 2006, que traz no currículo do curso de Pedagogia outros contextos para a atuação de seus profissionais, ou seja, "O egresso do curso de Pedagogia deverá estar apto a: trabalhar em espaços escolares e nãoescolares, na promoção da aprendizagem de sujeitos em diferentes fases do desenvolvimento humano, em diversos níveis e modalidades do processo educativo" (Brasil, 2006, p. 2).

Diante desse novo contexto, seja escolar ou não escolar, as competências atribuídas ao Pedagogo, Libâneo (2010) distingue a formação desse profissional como stricto sensu, por possibilitar a sua atuação em espaços educacionais de caráter formal, informal ou não formal, atendendo as necessidades sociais e tecnológicas da sociedade.

$\mathrm{O}$ autor ainda corrobora assinalando acerca do perfil pedagogo como sendo um "profissional que atua em várias instâncias da prática educativa, direta ou indiretamente ligadas à organização e aos processos de transmissão e assimilação ativa de saberes e modos de ação, tendo em vista objetivos de formação humana definidos em sua contextualização histórica" 
(Libânio, 2010, p.52). Entendemos, assim, que o pedagogo pode atuar em múltiplos espaços e não apenas dentro de uma sala de aula, porém, sua inserção em outros contextos não educacionais deve possuir ainda uma prática de caráter educativo e pedagógico, uma vez que não existe um estilo único de ensinar e aprender. Aferindo desta ideia, Vigotski (2007, p.95), colabora quando diz que: "De fato, aprendizado e desenvolvimento estão inter-relacionados desde o primeiro dia de vida da criança", ressaltando que a aprendizagem, portanto, não se faz só dentro da escola, acontece em todo ambiente de vivência.

Partindo do exposto acima, trazemos a Pedagogia Hospitalar como espaço não escolar, local onde o pedagogo é requisitado para dar continuidade aos estudos de crianças hospitalizadas que tiveram seus estudos interrompidos por consequência de sua condição de saúde, desta forma "assegurar o acesso à educação básica e à atenção às necessidades educacionais especiais, de modo a promover o desenvolvimento e contribuir para a construção do conhecimento desses educandos" (Brasil, 2002, p.07).

Ao pedagogo que atua no espaço hospitalar e presta atendimento pedagógico domiciliar, cabe organizar "estratégias e orientações para possibilitar o acompanhamento pedagógico-educacional do processo de desenvolvimento e construção do conhecimento" (Brasil, 2002, p.13) de crianças e jovens adolescentes ou quaisquer um que necessite de educação escolarizado no ensino regular, mas que por motivos de saúde não podem frequentar a escola e por vezes se encontram hospitalizados. A necessidade de ter um pedagogo neste espaço se torna imprescindível, principalmente para atender e assegurar um direito legitimado e vigente para essas crianças e adolescentes que têm o direito à saúde e à educação como é garantido pela Lei 8.069/90, que dispõe sobre o Estatuto da Criança e do Adolescente, nos artigos $3^{\circ} \mathrm{e} 4^{\circ}$, que garante:

Art. $3^{\circ} \mathrm{A}$ criança e o adolescente gozam de todos os direitos fundamentais inerentes à pessoa humana, sem prejuízo da proteção integral de que trata esta Lei, assegurando-se-lhes, por lei ou por outros meios, todas as oportunidades e facilidades, a fim de lhes facultar o desenvolvimento físico, mental, moral, espiritual e social, em condições de liberdade e de dignidade.

Art. $4^{\circ}$ É dever da família, da comunidade, da sociedade em geral e do poder público assegurar, com absoluta prioridade, a efetivação dos direitos referentes à vida, à saúde, à alimentação, à educação, ao esporte, ao lazer, à profissionalização, à cultura, à dignidade, ao respeito, à liberdade e à convivência familiar e comunitária (Brasil,1990).

Dessa forma, favorece à criança e ao adolescente um retorno à escola sem maiores perdas cognitivas, haja vista a atuação do pedagogo no espaço não escolar, possibilitando-os ao retorno ao ensino regular quando puder frequentar regularmente. Devemos ressaltar que, além do direito à educação e a função do pedagogo como educador, este ainda deve trabalhar de forma significativa e afetuosa, oportunizando uma significação ao aluno/paciente nesse momento delicado vivenciado por eles. Esse profissional deve ter empatia por seus alunos/pacientes, de forma a fazer com que eles se sintam queridos e confortáveis, apesar da situação em que se encontram, já que muitas vezes o ambiente hospitalar é hostil e por vezes arraigado de tristeza.

Nesse sentido, cabe então ao pedagogo buscar uma harmonia e apaziguar entre a tristeza e a dor que envolve o aluno/paciente e a família, entre o ensinar e o aprender, entre o saber e a dúvida, entre a incerteza e a certeza. Dessa forma, enfatizamos que o papel do pedagogo neste espaço se torna mais árdua do que se imagina, mais intenso do que prever as leis, mais intensa que o próprio eu, isso porque esse profissional tem que ser o elo entre a razão e a esperança, no processo que por vezes é mais pesado do que se imaginava, em que o fazer pedagógico dá um sentido mais alegre e harmônico entre a vivência e conivência no hospital. Este também é a ponte fundamental entre a escola e o hospital, no qual ele seja um efeito amenizador das dores provocadas no interior dos hospitais e a ponte que liga o aluno/paciente a sua vida estudantil, que pode ser uma das fases mais importantes para a criança e os adolescentes em sua totalidade, como também leva em consideração as partes específicas do seu desenvolvimento, no qual estão a afetividade e a cognição como um par dialético como discutiremos a seguir. 


\section{Arcabouço Teórico e Metodológico da Pesquisa}

Para a realização de uma pesquisa é relevante a escolha da metodologia que deverá ir ao encontro da base teóricometodológica que constitui as normas e procedimentos a serem utilizados no processo de obtenção/produção, análise e síntese de informações, da realidade pesquisada. Com isso, optamos pela pesquisa de campo de natureza qualitativa baseada no método dialético. Segundo Pereira (2018, p. 28) o método dialético "Empregado em pesquisa qualitativa, considera que os fatos não podem ser considerados fora de um contexto social; as contradições se transcendem dando origem a novas contradições que requerem soluções;". Doravante, entendemos que esse processo implica na reflexão permanente, tanto por parte do pesquisador quanto do sujeito pesquisado, resultando em transformações de ambos.

Assim, para subsídio da pesquisa, elegemos os pressupostos teórico-metodológicos da Psicologia Sócio-Histórica, a qual se sustenta na matriz filosófica do materialismo histórico e dialético e tem como principiante Vigotski e seus colaboradores Luria e Leontiev. Tais, pressupostos orientam o olhar do pesquisador, em relação ao que é pesquisado. Essa perspectiva nos permite romper com dicotomias, com posições irredutíveis, superar visões pautadas pela aparência, desvinculadas do todo.

Por ser criativo, produtor e transformador, o sujeito vai se desenvolvendo ao longo da sua vida, na relação com o outro, por meio dos instrumentos sociais e culturais disponíveis na sociedade, através das mediações entre o mundo objetivo e subjetivo, apreendendo assim a realidade para transformá-la

Com essa posição, adentramos no ambiente hospitalar, para produzir informações via entrevista, conversas e diálogos que se constituíram nas relações estabelecidas com a pedagoga que atua no espaço da pedagogia hospitalar na qual realizamos a investigação empírica. Assim, adentramos na realidade do sujeito investigado. Para este processo, adotamos os três princípios teórico-metodológicos que compõem a base da abordagem de análise das funções psicológicas superiores apresentadas por Vigotski (2007).

O primeiro princípio afirma que os fenômenos humanos devem ser estudados em processo de transformação e mudanças. O segundo princípio indica que a simples descrição dos fatos não desvela as relações dinâmica-causais, reais, subjacentes aos fenômenos. O terceiro princípio básico da abordagem Sócio-Histórica - o problema do comportamento fossilizado - explica a posição de Vigotski segundo a qual estudar algo significativo historicamente implica estudá-lo no processo de mudança,

Partindo desse pressuposto, acreditamos no processo de significação e transformação do homem em contato com a atividade que realiza por intermédio da subjetividade. Na perspectiva teórico-metodológica advinda da Psicologia SócioHistórica, o sujeito se revela tanto na dimensão social, no seu contato e desenvolvimento com a sociedade em que vive, como na sua dimensão individual, que perpassa o social. Ou seja, a transformação humana perpassa pelo processo de subjetividade que é constituída na relação do homem com o mundo material e social, existente pela atividade humana (Bock, 2015).

Nessa direção, Soares (2006, p. 34) concerne que o sujeito é “[...] uma síntese das múltiplas relações complexas estabelecidas nos espaços sociais em que atua, modificando e sendo modificado pelos elementos que constituem essas relações complexas".

Assim, intentamos em dizer o quanto a Psicologia Sócio-Histórica é importante nesta pesquisa, visto que almejamos nos aproximar das mediações que são constituídas nas relações subjetivas dessa egressa do curso de Pedagogia no espaço hospitalar, sabendo que ela se constitui nestas relações, sendo produto do meio social e, portanto, um ser ativo, dinâmico, social e histórico, sendo que é por meio da subjetividade, que é algo particular do indivíduo, que esse processo de constituição acontece. No entanto, essa subjetividade ocorre nas mediações do homem com o social. Com base nesse entendimento, destacamos a seguinte compreensão sobre subjetividade, em que "[...] a subjetividade delimita o conjunto de experiências dos 
sujeitos. E, nesse conjunto, está a experiência do conhecimento sobre as próprias experiências do sujeito" (Gonçalves, 2015, p. 53).

Nesse sentido, tanto a atividade, quanto as significações são permeadas pela subjetividade, porque perpassa toda constituição histórica e social do sujeito por meio da suas interações sociais. Em consonância a essas mediações subjetivas acontece nesse processo constitutivo do sujeito a presença da categoria afetividade como elemento constitutivo nessa interface. Assim, conforme Soares (2006, p. 57), "A afetividade é um grande elemento mediador presente nos espaços das relações sociais do sujeito". Dessa maneira, esses afetos construídos no espaço hospitalar medeia as relações subjetivas, permitindo abarcar a atividade da egressa, quanto também dos sujeitos presentes nesta vivência.

Nesse viés, como instrumento para a produção das informações optamos pela entrevista reflexiva por ser capaz de nos viabilizar um ambiente de aproximação entre entrevistador e o entrevistado, isso porque essa ferramenta (entrevista reflexiva) possui um formato aberto que permite a interação entre os sujeitos envolvidos da pesquisa, o pesquisador e o pesquisado, e assim vem superando a visão de entrevista em que o sujeito entrevistado se põe na posição de mero informante (Szymanski, 2011).

Ainda segundo Szymanski (2011, p.12), a entrevista feita face a face "é fundamentalmente uma situação de interação humana, em que estão em jogo as percepções do outro e de si, expectativas, sentimentos, preconceitos e interpretações para os protagonistas: entrevistador e entrevistado". Para a realização dessa entrevista, foi desenvolvido um roteiro para nortear todo procedimento sem perdermos o foco do que é perguntado ao sujeito entrevistado.

Esse roteiro foi elaborado por perguntas abertas e semi-estruturada, que possibilitaram tanto a entrevistada quanto entrevistadoras avançar em questões além do que foi pensado, ou seja, apreensão das significações da egressa no curso de Pedagogia acerca do espaço não-escolar, proporcionando a nós compreendermos as relações subjetivas constituídas por essa docente diante da atividade que desenvolve.

Esse instrumento de produção de informação também possibilita um processo reflexivo no qual o entrevistado pode voltar à questão discutida e articulá-la de outra maneira em uma nova narrativa, ou seja, o sujeito entrevistado pode refazer as suas falas, ao mesmo tempo em que consente ao entrevistador a aquisição de maior quantidade de informações, mas sem perder a essência do seu significado (Szymanski, 2011).

Com as informações obtidas, realizamos o tratamento das informações utilizando os núcleos de significação como procedimento de análises que objetiva compreender as relações subjetivas constituídas por uma egressa do curso de Pedagogia no espaço não-escolar. Com isso, é de suma importância que fiquemos em consenso com os princípios teórico metodológicos da Psicologia Sócio-Histórica. Dessa forma, encontramos no processo de aglutinação dos núcleos de significação um meio importante para extrairmos das falas do sujeito os pré-indicadores, que são trechos das falas da egressa, que carregam sentidos e significados e são em grande número.

\section{Resultados e Discussão}

Neste, apresentamos a sistematização dos indicadores, e conseguinte a constituição e nomeação do núcleo de significação, para que o leitor, em linguagem visual, possa compreender como ocorre a construção dos núcleos de significação: 
Quadro 1 - Apresentação dos Pré-indicadores, Indicadores e Núcleos de significação.

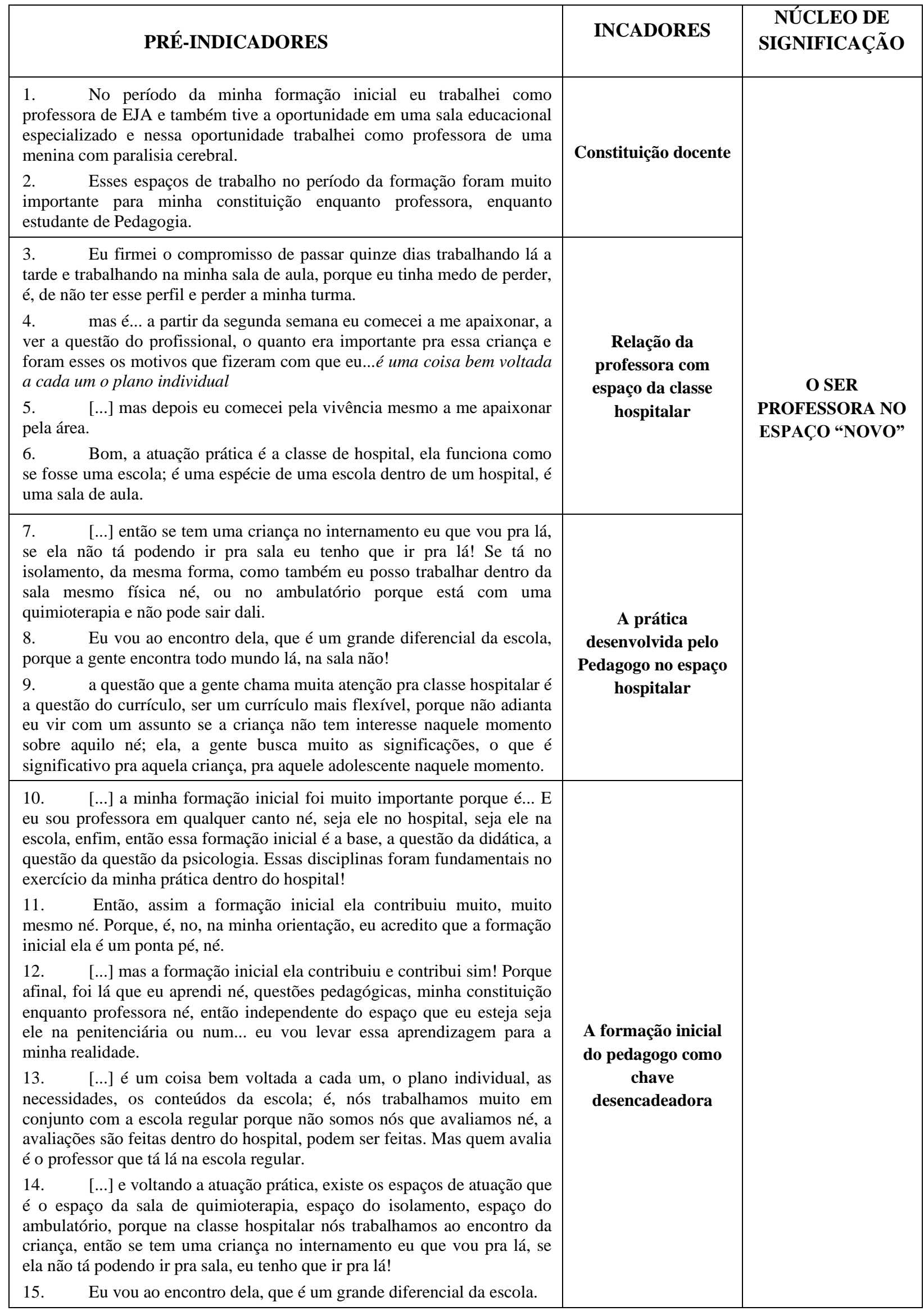


Assim, o quadro denota a constituição do núcleo de significação O SER PROFESSORA NO ESPAÇO "NOVO", mostrando o movimento de ir e vir, que constitui o percurso utilizado no procedimento de análise dos núcleos de significação. Esse percurso inicia-se com os pré-indicadores - fala com significado da colaboradora, os indicadores- aglutinação considerando as semelhanças e articulações entre os temas/conteúdos e finalizando com a sistematização do núcleo de significação- tendo como critério a articulação dos conteúdos semelhantes, complementares ou contraditórios.

Após a sistematização acima apresentada, lançamos mão do procedimento dos núcleos de significação para respaldar a nossa inquietação: primeiro, utilizamos tal procedimento para buscar compreender as relações subjetivas constituídas por uma egressa do curso de Pedagogia inserida neste novo campo de trabalho, em especial o campo hospitalar.

Iniciamos nossa análise apresentando os indicadores, que segundo Aguiar e Ozella (2006; 2013), se aproximam por similaridade e complementaridade, e/ou contraposição. Nessa perspectiva, o primeiro indicador: CONSTITUIÇÃO DOCENTE foi pensado, porque durante a entrevista, a professora falou o quanto as experiências vivenciadas na Educação de Jovens e Adultos a constituiu como docente da classe hospitalar. Essa relevância é mostrada em sua fala:

No período da minha formação inicial eu trabalhei como professora de EJA e também tive a oportunidade em uma sala educacional especializada e nessa oportunidade trabalhei como professora de uma menina com paralisia cerebral.

Esses espaços de trabalho no período da formação foram muito importantes para minha constituição enquanto professora, enquanto estudante de Pedagogia.

Dessa maneira, destacando a significância da constituição docente, a fala da professora ressalta elementos da sua vivência, enquanto sujeito histórico, cultural e social. Aquilo que subjetivamos em contato com o mundo e o meio social em que coabitamos, torna-se único, particular, singular. Sendo assim, a nossa subjetividade é individual, no entanto, aponta traços constitutivos da sociedade em que esse homem está inserido. Nesse entendimento, Gonçalves (2015, p. 56) aponta que "no materialismo histórico e dialético, o homem só é indivíduo, ou melhor, só se constitui individuo porque é social e histórico". Assim, as relações vividas durante a sua formação inicial foram importantes para que essa se institua como uma professora de classe hospitalar.

Apresentamos o segundo indicador: RELAÇÃO DA PROFESSORA COMO ESPAÇO DA CLASSE HOSPITALAR. Este indicador tem sua relevância por revelar a relação afetuosa que a professora demonstra no seu exercício docente e o quanto se apaixonou pelo trabalho, algo muito significativo para ela. Nos pré-indicadores4 e 5, notamos essa importância:

[...] ] partir da segunda semana, eu comecei a me apaixonar, a ver a questão do profissional o quanto era importante pra essa criança e foram esses os motivos que fizeram com que eu [...].

[...] depois eu comecei pela vivência mesmo a me apaixonar pela área.

Dessa forma, fica evidente a mediação dos afetos no processo de constituição dessa professora por meio da subjetividade que vivencia no espaço do hospital. Isso é revelado no seguinte trecho: "depois eu comecei pela vivência mesmo a me apaixonar pela área", em que utiliza o sentimento da paixão para justificar a sua afetação, pelo seu campo de atuação.

Sendo assim, segundo Luppi e Alves (2019, pp. 118-119)

[...] tanto a afetividade quanto cognição são elementos fundamentais para a construção e o entendimento do sujeito, entendendo que o desenvolvimento das funções cognitivas e afetivas estão fortemente relacionados às bases biológicas, ao mesmo tempo em que estão imersas no social. Assim, a cognição, bem como a afetividade emergem das funções orgânicas que se mostram como um aparato importante, mas que vai conferindo certa complexidade e diferenciação na relação dialética com o social 
Destarte, para a Psicologia Sócio-Histórica a afetividade se constitui numa das mais importantes categorias de análise para compreensão do sujeito. Assim sendo, tanto o afetivo quanto cognitivo são elementos indissociáveis para compreensão e transformação do sujeito.

O terceiro indicador se estabelece como: A PRÁTICA DESENVOLVIDA PELO PEDAGOGO NO ESPAÇO HOSPITALAR. Falar da prática foi uma forma que significou muito para a professora, pois ela demonstrou ser compromissada com a aprendizagem dos alunos em tratamento oncológico e dispôs dos meios utilizados pelos professores para que essa aprendizagem viesse acontecer. Isso fica evidente na sua fala:

[...] então se tem uma criança no internamento eu que vou pra lá, se ela não tá podendo ir pra sala eu tenho que ir pra lá! Se tá no isolamento, da mesma forma, como também eu posso trabalhar dentro da sala mesmo física né, ou no ambulatório porque está com uma quimioterapia e não pode sair dali.

[...] a questão que a gente chama muita atenção pra classe hospitalar é a questão do currículo, ser um currículo mais flexivel, porque não adianta eu vir com um assunto se a criança não tem interesse naquele momento sobre aquilo, né; ela, a gente busca muito a significações, o que é significativo pra aquela criança, pra aquele adolescente naquele momento.

$\mathrm{Na}$ fala da professora, fica visível o movimento flexível que ela utiliza para que o aluno queira estudar e aprender aquele conteúdo, não se resumindo apenas em atividades pedagógicas aleatórias, mas que cause significância tanto para o aluno, quanto para a professora.

A respeito disto, Furtado (2011, p. 68) expõe o seguinte entendimento:

[...] podemos afirmar que a partir da ação concreta no mundo (atividade), o ser humano passa a constituir aspectos subjetivos de registros e significação que lhe permitem a produção de sentidos que acompanham (sem ser reflexo) sua ação no mundo.

Nesse sentido, compreendemos o processo de constituição humana como um processo que está diretamente relacionado com os elementos subjetivos providos da interação social, tais como: aspectos culturais, históricos e sociais e que a categoria da atividade tem um importante papel nessa arte. Isto é, buscamos atividades em que o sujeito tenha uma reflexão crítica sobre o seu fazer, não se restringindo a uma mera repetição de práticas e ações mecanizadas.

O quarto indicador tem como eixo A FORMAÇÃO INICIAL DO PEDAGOGO COMO CHAVE DESENCADEADORA. O indicador em questão trata da importância da formação inicial elucidada na fala da egressa, para que atualmente ela tenha uma reflexão-crítica da e sobre a prática pedagógica que desenvolve na classe hospitalar, como evidenciado na fala a seguir:

[...] mas a formação inicial ela contribuiu e contribui sim! Porque afinal, foi lá que eu aprendi né, questões pedagógicas, minha constituição enquanto professora né, então independente do espaço que eu esteja, seja ele na penitenciária ou num... eи vou levar essa aprendizagem para a minha realidade.

$\mathrm{Na}$ fala da professora, percebemos a importância do contato primeiro de qualquer profissional com o ensino, para que este, em sua atuação profissional, possa repensar sua prática cotidiana nas atividades curriculares dos estudantes. Nos préinidicadores 13 e 14, fica explícito esse cuidado:

[...] é uma coisa bem voltada a cada um, o plano individual, as necessidades, os conteúdos da escola; é, nós trabalhamos muito em conjunto com a escola regular porque não somos nós que avaliamos né, a avaliações são feitas dentro do hospital, podem ser feitas. Mas quem avalia é o professor que tá lá na escola regular. 
[...] e voltando a atuação prática, existe os espaços de atuação que é o espaço da sala de quimioterapia, espaço do isolamento, espaço do ambulatório, porque na classe hospitalar nós trabalhamos ao encontro da criança, então se tem uma criança no internamento eu que vou pra lá, se ela não tá podendo ir pra sala, eu tenho que ir pra lá!

O movimento realizado pela professora de refletir, pensar sempre no aluno, torna perceptível as significações atribuídas por ela na efetivação da prática docente, constituindo-se como profissional e humana, em um movimento dialético.

A síntese do movimento de pré-indicadores e indicadores resultou no núcleo de significação: $\boldsymbol{O}$ SER PROFESSORA NO ESPAÇO "NOVO", como respaldo às significações reveladas na análise inter-núcleo. Esse espaço "novo", caracterizado por nós dessa forma, contribuiu para desvelar as significações vivenciadas pela pedagoga em sua atividade docente, sua atuação humana.

\section{Considerações Finais}

Este trabalho nos viabilizou compreender o processo de constituição de uma egressa do curso de Pedagogia no espaço não escolar, mediado pelas relações subjetivas presente no espaço da Pedagogia Hospitalar, partindo das interações humanas existentes neste ambiente social e educativo, visto que, são nessas vivências que a egressa se refaz em meio à subjetividade do mundo material e social, revelada na transformação de sua atividade, no fazer a docência acontecer, mesmo que as condições de saúde das crianças, jovens estejam comprometidas.

Assim, essa egressa passa a refletir sua ação pedagógica em uma união do afetivo com o cognitivo e movida pelos afetos que a constitui como professora da classe hospitalar, reflete seu ser docente e faz com que o processo de ensinoaprendizagem dos assistidos aconteça. A sua relação com os conhecimentos que a constituíram e a constituem possibilita desenvolver a sua prática profissional influenciada na condição de pedagoga hospitalar, pois, partimos do princípio de que somos sujeitos e estamos em constante processo de formação em um movimento dialético.

Com isso, a subjetividade presente no cotidiano dessa educadora foi retratada a partir do momento em que essa docente busca uma prática, entendendo as dificuldades apresentadas pelos alunos, seus anseios; e a reflexão a conduz em uma busca da transformação da atividade, nos aproximando da compreensão das relações subjetivas presente no espaço da educação não-escolar.

Para futuros trabalhos propomos criar estratégias de ensino-aprendizagem a serem trabalhadas com alunos em formação inicial do curso de Pedagogia, e com professores que atuam na pedagogia hospitalar, promovendo oficinas pedagógicas, minicursos, tendo como foco aprendizagem e desenvolvimento dos licenciandos e professores na atuação formativa.

\section{Agradecimentos}

A Universidade do Estado do Rio Grande do Norte/ UERN; Ao Programa de Pós-Graduação em Educação/ POSEDUC/UERN e ao Grupo de Estudo e Pesquisa em Educação e Subjetividade - GEPES, da Universidade do Estado do Rio Grande do Norte/UERN, pelas contribuições para a construção desse estudo.

\section{Referências}

Aguiar, W. M. J. \& Ozella, S. (2006). Núcleos de significação como instrumento para a apreensão da constituição dos sentidos. Psicologia: Ciência e Profissão. 26 (2), 222-245.

Aguiar, W. M. J. \& Ozella, S. (2013). Apreensão dos sentidos: aprimorando a proposta dos núcleos de significação. Revista Brasileira de Estudos Pedagógicos. 94 (236), 299-322.

Aguiar, W. M. J. Soares, J. R. \& Machado, V. C. (2015). Núcleos de Significação: uma proposta histórico-dialética de apreensão das significações. Cadernos de Pesquisa, 45 (155), 56-75. 
Research, Society and Development, v. 10, n. 4, e47710413898, 2021

(CC BY 4.0) | ISSN 2525-3409 | DOI: http://dx.doi.org/10.33448/rsd-v10i4.13898

Bock, A. M. B. (2015). A Psicologia Sócio-Histórica: uma perspectiva crítica em Psicologia. In: Bock, A. M. B.; Gonçalves, M. G. M.; Furtado, O. (orgs.). Psicologia Sócio-Histórica: uma perspectiva crítica em Psicologia. (6a ed.), Cortez, 21-46.

Bock, A. M. B. \& Aguiar, W. M. J. (2016). A dimensão subjetiva: um recurso teórico para a Psicologia da Educação. In: Aguiar, W. M. J.; Bock, A. M. B. A Dimensão Subjetiva do Processo Educacional. Cortez, 43-59.

Brasil. (1990). Lei no 8.069, de 13 de julho de 1990. Dispõe sobre o Estatuto da Criança e do Adolescente e dá outras providências. Diário Oficial da União, Brasília, DF, 16 jul. 1990.

Brasil. Ministério da Educação. Secretaria de Educação Especial. (2002). Classe hospitalar e atendimento pedagógico domiciliar: estratégias e orientações. Brasília, DF: MEC/SEE. http://portal.mec.gov.br/seesp/arquivos/pdf/livro9.pdf.

Brasil. Conselho Nacional de Educação. (2006). Diretrizes Curriculares Nacionais para o Curso de Pedagogia do CNE. Resolução CNE/CP n.1 de 15 de maio de 2006. Diário Oficial da União, Brasília, DF. http://portal.mec.gov.br/cne/arquivos/pdf/rcp01_06.pdf.

Furtado, O. (2011). O Trabalho e a dimensão subjetiva da realidade (cap. 3). In: Furtado, O. Construindo o compromisso social da Psicologia:trabalho e solidariedade. Cortez, 63-98.

Gonçalves, M. G. M. (2015). A Psicologia do Sujeito e da Subjetividade: a historicidade como noção básica. In: Bock, A.M. B.; Gonçalves, M. G. M.; Furtado, O. (orgs.). Psicologia Sócio-Histórica: uma perspectiva crítica em psicologia. (6a ed.), Cortez, 47-92.

Libâneo, J. C. (2010). Pedagogia e pedagogos para quê? (12a ed.), Cortez.

Luria, A. R. (2001). Pensamento e linguagem: as últimas conferências de Luria. Artmed.

Pereira, A. S. et al. (2018). Metodologia da pesquisa cientifica. UFSM. https://repositorio.ufsm.br/bitstream/handle/1/15824/Lic_Computacao_MetodologiaPesquisa-Cientifica.pdf?

Soares, J. R. (2006). Vivência pedagógica: a produção de sentidos na formação do professor em serviço. Dissertação (Mestrado em Educação: Psicologia da Educação) - Pontifícia Universidade Católica de São Paulo, São Paulo.

Szymanski, H. (2011). Entrevista reflexiva: um olhar psicológico sobre a entrevista em pesquisa. In: Szymanski, H. (org.). A entrevista na pesquisa em educação: a prática reflexiva. Brasília: Liber Livro, 9-63.

Vigotski, L. S. (2009). A construção do pensamento e da linguagem. (2a ed.), Martins Fontes.

Vygotsky, L. S. (2007). Formação social da mente. (7a ed.), Martins Fontes. 